\title{
Porous Methyltrimethoxysilane Coated Nanoscale-Hydroxyapatite for Removing Lead Ions from Aqueous Solutions
}

\author{
C. S. Ciobanu, ${ }^{1}$ S. L. Iconaru, ${ }^{1,2}$ C. L. Popa, ${ }^{1,3}$ A. Costescu, ${ }^{4}$ \\ M. Motelica-Heino, ${ }^{2}$ and D. Predoi ${ }^{1}$ \\ ${ }^{1}$ National Institute of Materials Physics, P.O. Box MG 07, 077125 Magurele, Romania \\ ${ }^{2}$ ISTO, UMR 7327 CNRS Université d'Orléans, 1A rue de la Férollerie, 45071 Orléans Cedex 2, France \\ ${ }^{3}$ Faculty of Physics, University of Bucharest, 405 Atomistilor, P.O. Box MG-1, 077125 Magurele, Romania \\ ${ }^{4}$ Hyperion University of Bucharest, 169 Calea Călăraşilor, 030615 Bucharest, Romania
}

Correspondence should be addressed to D. Predoi; dpredoi@gmail.com

Received 4 April 2014; Revised 26 June 2014; Accepted 30 June 2014; Published 16 July 2014

Academic Editor: Arun Kumar

Copyright (C) 2014 C. S. Ciobanu et al. This is an open access article distributed under the Creative Commons Attribution License, which permits unrestricted use, distribution, and reproduction in any medium, provided the original work is properly cited.

\begin{abstract}
The aim of this study was to synthetize new porous nanoparticles based on methyltrimethoxysilane coated hydroxyapatite (MTHAp) for lead removal form aqueous solutions. The morphological and compositional analysis of MTHAp were investigated by X-ray diffraction (XRD), Fourier transform infrared spectroscopy (FTIR) and scanning electron microscopy (SEM) equipped with an energy dispersive X-ray spectrometer (EDS). Removal experiments of $\mathrm{Pb}^{2+}$ ions were carried out in aqueous solutions with controlled concentration of $\mathrm{Pb}^{2+}$ at a fixed $\mathrm{pH}$ value of 3 and 5 respectively. After the removal experiment of $\mathrm{Pb}^{2+}$ ions from solutions, porous hydroxyapatite nanoparticles were transformed into PbMTHAp_3 and PbMTHAp_5 via the adsorption of $\mathrm{Pb}^{2+}$ ions followed by a cation exchange reaction. The X-ray diffraction spectra of PbMTHAp_3 and PbMTHAp_5 revealed that the powders, after removal of the $\mathrm{Pb}^{2+}$ ions, were a mixture of $\mathrm{Ca}_{2.5} \mathrm{~Pb}_{7.5}\left(\mathrm{PO}_{4}\right)_{6}(\mathrm{OH})_{2}, \mathrm{~Pb}_{2} \mathrm{Ca}_{4}\left(\mathrm{PO}_{4}\right)_{2}\left(\mathrm{SiO}_{4}\right)$, and $\mathrm{Ca}_{10}(\mathrm{PO})_{6}(\mathrm{OH})_{2}$. Our results demonstrate that the porous hydroxyapatite nanoparticles can be used as an adsorbent for removing $\mathrm{Pb}^{2+}$ ions from aqueous solutions.
\end{abstract}

\section{Introduction}

One of the major environmental problems is represented by the global contamination with potentially toxic trace elements (PTTE). Lead has been widely used in the industrial field, for lead-based batteries, ammunition, paints, and building materials [1-4]. Due to their nonbiodegradable behaviour and their incapacity of metabolization and decomposition, PTTE like $\mathrm{Pb}, \mathrm{Cu}, \mathrm{Cd}, \mathrm{Zn}$, and $\mathrm{Hg}$ are the main contaminants of soils and ground or surface waters. Their progressive accumulation in the human body can cause significant health problems, inducing chronic illness which, when untreated, can lead to a painful death.

Among a large variety of PTTE, one of the most dangerous is lead. Because of its unique properties, such as resistance to corrosion, malleability, and poor conductibility, it has been used since ancient times for many applications being found in pipes, pottery, or pigments [5]. Over time, it has become more and more clear that lead exposure for a long period of time may cause many health problems, affecting the human reproductive, nervous, gastrointestinal, immune, renal, cardiovascular, skeletal, muscular, and hematopoietic systems $[5,6]$. Furthermore, it impairs the development process $[5,6]$. Recently, The International Agency for Research on Cancer (IARC) has included lead in the list of possible human carcinogens (IARC, 1987) together with its inorganic compounds (IACR 2006) [5]. Therefore, researchers worldwide have focused on developing new and improved methods for removing PTTE from different environmental compartments such as soils and waters. Nowadays, different 
methods such as chemical precipitation $[7,8]$, nanofiltration [7-9], reverse osmosis [7-10], and adsorption [7, 11-14] are used for depollution of water.

In the last decades, a major attention has been given to a special material, hydroxyapatite (HAp) $\left[\mathrm{Ca}_{10}\left(\mathrm{PO}_{4}\right)_{6}(\mathrm{OH})_{2}\right]$, due to its remarkable properties. Being the main inorganic constituent of bone and teeth and a natural source of phosphate, hydroxyapatite is widely used in the medical field for many orthopaedic, dental, and maxillofacial applications. On the other hand, hydroxyapatite has a high sorption capacity for actinides and divalent metals [15, 16]. Furthermore, previous studies have revealed a high capacity for removing divalent ions from aqueous solutions [17] and contaminated soils [15]. For the removal of PTTE from polluted media by synthetic HAp different mechanisms have been reported, like ion exchange [18] and substitution of $\mathrm{Ca}$ ions in HAp by metals ions $[15,18]$. In order to improve the capacity of adsorption, it was shown that there are several factors that must be taken into account, among them the type of divalent metal, the physicochemical properties of HAp, the metal concentration, the solution $\mathrm{pH}$, and so forth [19].

Thus, the aim of this study was to prepare methyltrimethoxysilane coated hydroxyapatite (MTHAp) composite powders at nanoscale and to investigate the removal of $\mathrm{Pb}^{2+}$ ions from aqueous solutions using MTHAp samples with different $\mathrm{pH}$ values of the solution.

\section{Materials and Methods}

The morphological and compositional analysis of MTHAp were investigated by X-ray diffraction (XRD), Fourier transform infrared spectroscopy (FTIR), and scanning electron microscopy (SEM) equipped with an energy dispersive X-ray spectrometer (EDS). Batch experiments at a fixed $\mathrm{pH}$ of 3 and 5 were conducted with the powders and solutions of lead.

2.1. Experimental Section. All the reagents for the HAp synthesis, including ammonium dihydrogen phosphate $\left[\left(\mathrm{NH}_{4}\right)_{2} \mathrm{HPO}_{4}\right]$ (Alpha Aesar) and calcium nitrate $\left[\mathrm{Ca}\left(\mathrm{NO}_{3}\right)_{2} \cdot 4 \mathrm{H}_{2} \mathrm{O}\right]$ (Alpha Aesar), were purchased without further purification. Methyltrimethoxysilane (MTMS, $\left.\mathrm{H}_{3} \mathrm{C}-\mathrm{Si}-\left(\mathrm{OCH}_{3}\right)_{3}\right)$ was purchased from Merck (Darmstadt, Germany). Lead nitrate $\left[\mathrm{Pb}\left(\mathrm{NO}_{3}\right)_{2}\right]$ and extra pure $\mathrm{HCl}$ solution acquired from Merck were used for adjusting the initial $\mathrm{Pb}^{2+}$ ion concentration and $\mathrm{pH}$ value in the aqueous solutions.

2.2. Preparation of Methyltrimethoxysilane Coated Hydroxyapatite (MTHAp). Methyltrimethoxysilane coated hydroxyapatite (MTHAp) was synthesized using as precursors methyltrimethoxysilane and hydroxyapatite. The hydroxyapatite $\left(\mathrm{Ca}_{10}\left(\mathrm{PO}_{4}\right)_{6}(\mathrm{OH})_{2}\right.$, HAp) was immobilized into a methyltrimethoxysilane foam using the technique reported in literature [20, 21]. In accord with [21], the atomic ratio $\mathrm{Ca} / \mathrm{P}$ was set at 1.67 for obtaining pure HAp. The MTHAp was achieved by dropping the solution containing methyltrimethoxysilane $(1 \mathrm{~g} \mathrm{HAp} / 10 \mathrm{~mL})$ onto HAp powders after the last centrifugation. The mixture was then stirred vigorously for $1 \mathrm{~h}$ until homogeneity was achieved. The final MTHAp composites were dried in a vacuum oven at $80^{\circ} \mathrm{C}$ for $72 \mathrm{~h}$. To obtain the powders, the MTHAp composite samples were ground after drying.

\subsection{Removal Experiment of $\mathrm{Pb}^{2+}$ Ions in Aqueous Solution.} Removal performance of $\mathrm{Pb}^{2+}$ ions by the MTHAp composite powders was investigated by batch experiments, monitoring the change of $\mathrm{Pb}^{2+}$ ion concentration in the aqueous solution. For these experiments, $5 \mathrm{~g}$ of MTHAp composite sample was added to $500 \mathrm{~mL}$ aqueous solution with various initial $\mathrm{Pb}^{2+}$ ion concentrations and $\mathrm{pH}$ values in accord with Jang et al. [17]. The initial $\mathrm{Pb}^{2+}$ ion concentrations of the aqueous solutions were controlled and the values were set in the range $0.1-0.9 \mathrm{~g} \cdot \mathrm{L}^{-1}$ by dissolving lead nitrate $\left[\mathrm{Pb}\left(\mathrm{NO}_{3}\right)_{2}\right]$ in deionized water. The $\mathrm{pH}$ values of aqueous solutions with a controlled initial $\mathrm{Pb}^{2+}$ ion concentration were adjusted from 5 to 3 by adding small amounts of $0.1 \mathrm{M} \mathrm{HCl}$ standard solution. For all experiments the solution was stirred constantly for $24 \mathrm{~h}$ by a mechanical stirrer at room temperature.

2.4. Characterization. The functional groups present in the prepared powders were identified by FTIR (Spectrum BX Spectrometer). For this, $1 \%$ of the powder was mixed and ground with $99 \% \mathrm{KBr}$. Pellets of $10 \mathrm{~mm}$ diameter for FTIR measurements were prepared by pressing the powder mixture at a load of 5 tons for $2 \mathrm{~min}$ and the spectrum was taken in the range of 400 to $4000 \mathrm{~cm}^{-1}$ with a resolution of 4 and 128 times scanning. The X-ray diffraction spectra for the MTHAp samples were recorded using a Bruker D8 Advance diffractometer, with nickel filtered $\mathrm{Cu} K_{\alpha}(\lambda=1.5405 \AA)$ radiation. The diffraction patterns were collected in the $2 \theta$ range $20^{\circ}-$ $60^{\circ}$, with a step of $0.02^{\circ}$ and $34 \mathrm{~s}$ measuring time per step. Scanning electron microscopy (SEM) study was performed on a HITACHI S2600N-type microscope equipped with an energy dispersive $\mathrm{X}$-ray attachment (EDAX/2001 device). The concentration of $\mathrm{Pb}^{2+}$ ions remaining in the solution after the MTHAp reacted with the $\mathrm{Pb}^{2+}$ ion-containing solution was determined by flame atomic absorption spectroscopy (Hitachi Z-8100 spectrophotometer).

The amount of retained lead ion concentration was obtained using atomic absorption. The removal efficiency of lead ions was calculated using the following formula:

$$
R(\%)=\frac{C_{o}-C_{e}}{C_{o}} \cdot 100,
$$

where $C_{o}$ and $C_{e}$ are the initial and the equilibrium concentration of $\mathrm{Pb}^{2+}(\mathrm{g} / \mathrm{L})$.

The adsorption isotherm was also obtained by mixing a solution with different initial concentrations of $\mathrm{Pb}^{2+}$ with a known amount of hydroxyapatite coated with methyltrimethoxysilane powder until the equilibrium was achieved. The sorption capacity representing the amount of metal retained on the unit mass of sorbent at the equilibrium 


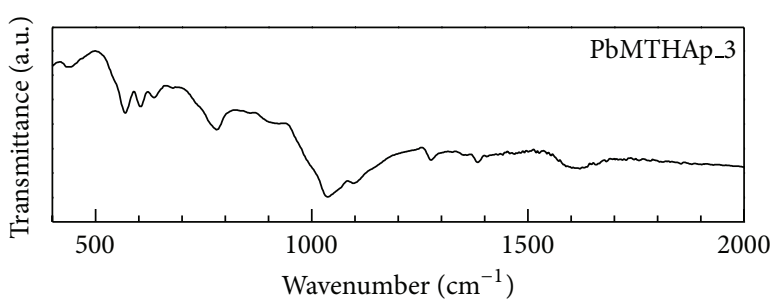

(a)

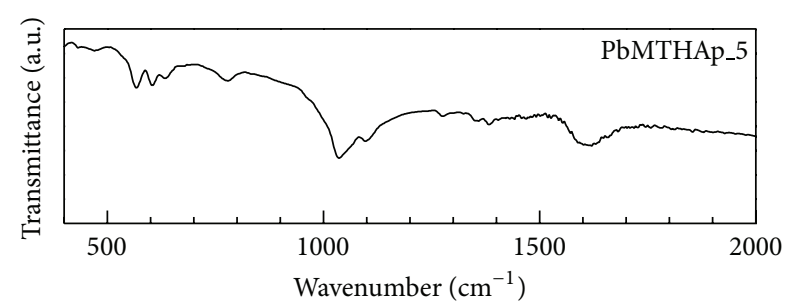

(b)

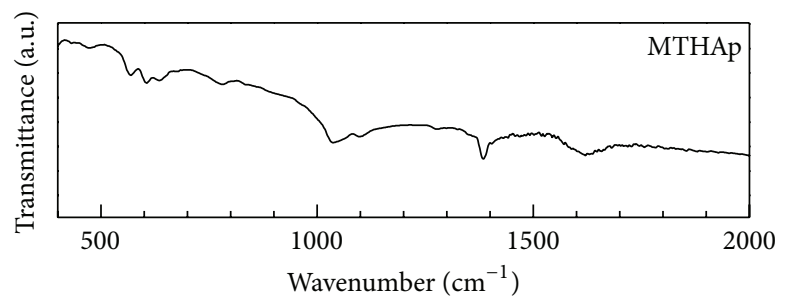

(c)

FIGURE 1: FTIR spectra of hydroxyapatite coated with methyltrimethoxysilane before (MTHAp) and after removal experiment of $\mathrm{Pb}^{2+}$ at $\mathrm{pH}$ 5 (PbMTHAp_5) and pH 3 (PbMTHAp_3).

was also estimated. The amount adsorbed at equilibrium, $q_{e}$, was calculated with the following formula:

$$
q_{e}=\frac{\left(C_{o}-C_{e}\right) \cdot V}{m}
$$

where $C_{0}$ is initial concentration, $(\mathrm{mg} / \mathrm{L}) ; C_{e}$ is equilibrium concentration, $(\mathrm{mg} / \mathrm{L}) ; V$ is volume of solution, $(\mathrm{L}) ; m$ is adsorbent quantity, (g).

\section{Results and Discussions}

The FTIR spectra of the methyltrimethoxysilane coated hydroxyapatite powder before (MTHAp) and after the removal experiment of $\mathrm{Pb}^{2+}$ ions at $\mathrm{pH} 5$ (PbMTHAp_5) and $\mathrm{pH} 3$ (PbMTHAp_3) are shown in Figure 1. The most noticeable feature in these spectra concerns the presence of the typical $\nu_{4} \mathrm{PO}_{4}{ }^{3-}$ and $\nu_{3} \mathrm{PO}_{4}{ }^{3-}$ bands $[22,23]$. The bands present in the ranges $530-650 \mathrm{~cm}^{-1}$ and $900-1200 \mathrm{~cm}^{-1}$ correspond to IR vibrations of phosphate group belonging to apatite $[24,25]$.

The band at $475 \mathrm{~cm}^{-1}$ can be attributed to the $v_{2} \mathrm{PO}_{4}{ }^{3-}$ vibrational mode. According to Gibson et al. [26] the incorporation of silicon in the HAp lattice affects the FTIR spectra of HAp, in particular the $\mathrm{P}-\mathrm{O}$ vibrational bands. In previous studies realised by Karakassides et al. [27] and Bogya et al. [28] it was shown that the distortion is caused by the stretching vibrations assigned to the $\mathrm{Si}-\mathrm{O}-\mathrm{Si}$ bonds that should appear in the range of $950-1200 \mathrm{~cm}^{-1}$. Due to the presence of the phosphate groups in the range of 950$1200 \mathrm{~cm}^{-1}$, the peaks associated to $\mathrm{Si}-\mathrm{O}-\mathrm{Si}$ bonds cannot be observed $[29,30]$. In addition, the band which appears at $631 \mathrm{~cm}^{-1}$ is assigned to the vibrational stretching mode of $\mathrm{OH}$ in the apatite lattice. Moreover, the band at around $3435 \mathrm{~cm}^{-1}$ is assigned to the water adsorbed on the surface. Another characteristic peak of the adsorbed water appears at
$1640 \mathrm{~cm}^{-1}$, due to $\mathrm{O}-\mathrm{H}$ bending. According to Zhai et al. [31] the bands around $3400 \mathrm{~cm}^{-1}$ are due to $\mathrm{O}-\mathrm{H}$ stretching of water associated to crystallization.

Figure 2 presents the X-ray diffraction patterns of the methyltrimethoxysilane coated hydroxyapatite powder before (MTHAp) and after the removal experiment of $\mathrm{Pb}^{2+}$ ions at $\mathrm{pH} 5$ (PbMTHAp_5) and $\mathrm{pH} 3$ (PbMTHAp_3), respectively. All the diffraction peaks of MTHAp powders could be assigned to the standard characteristic peaks of hexagonal hydroxyapatite and no secondary phases were detected, indicating that the phase of the samples was of pure HAp [20]. The diffraction patterns support the fact that HAp nanoparticles were successfully coated with methyltrimethoxysilane without any structural changes. The hydroxyapatite coated with methyltrimethoxysilane composite was likely to be transformed into PbMTHAp via the adsorption of $\mathrm{Pb}^{2+}$ ions followed by the cation exchange reaction [32].

The spectra of PbMTHAp_5 and PbMTHAp_3 revealed that the powders after the removal of $\mathrm{Pb}^{2+}$ were a mixture of $\mathrm{Ca}_{2.5} \mathrm{~Pb}_{7.5}\left(\mathrm{PO}_{4}\right)_{6}(\mathrm{OH})_{2}, \mathrm{~Pb}_{2} \mathrm{Ca}_{4}\left(\mathrm{PO}_{4}\right)_{2}\left(\mathrm{SiO}_{4}\right)$ (represented by $*$ in the $\mathrm{XRD}$ spectra), and $\mathrm{Ca}_{10}\left(\mathrm{PO}_{4}\right)_{6}(\mathrm{OH})_{2}$. In previous studies on the removal of lead ions from aqueous solution by a phosphosilicate glass, Kim et al. [33] showed that, at pH 3 and 5, only $\mathrm{Pb}_{10}\left(\mathrm{PO}_{4}\right)_{6}(\mathrm{OH})_{2}$ crystals formed on the glass when the glass reacted with the solution containing $\mathrm{Pb}^{2+}$ ions. On the other hand, Zhang et al. [34], in their recently study on the efficient and selective immobilization of $\mathrm{Pb}^{2+}$ in a highly acidic wastewater using strontium hydroxyapatite nanorods, showed that the final solids were a mixture of SrHAp, $\mathrm{PbHPO}_{4}$, and $\mathrm{Pb}_{5}\left(\mathrm{PO}_{4}\right)_{3}(\mathrm{OH})$.

The hydroxyapatite coated with methyltrimethoxysilane before and after the reaction with the $\mathrm{Pb}^{2+}$ ion-containing solution with $\mathrm{pH} 3$ and 5 for $24 \mathrm{~h}$ was investigated by SEM and the results are presented in Figure 3. The SEM investigations suggest that the solid reaction products of aqueous $\mathrm{Pb}$ with 


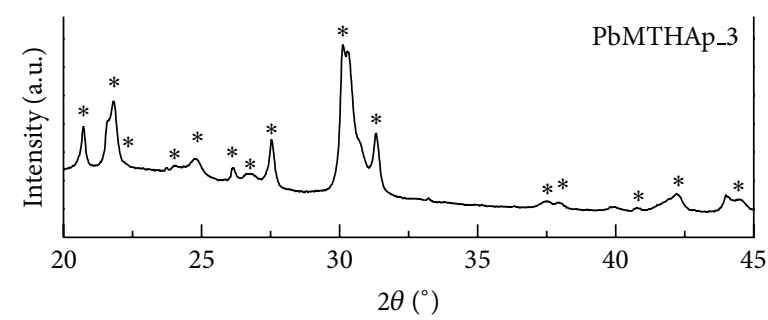

(a)

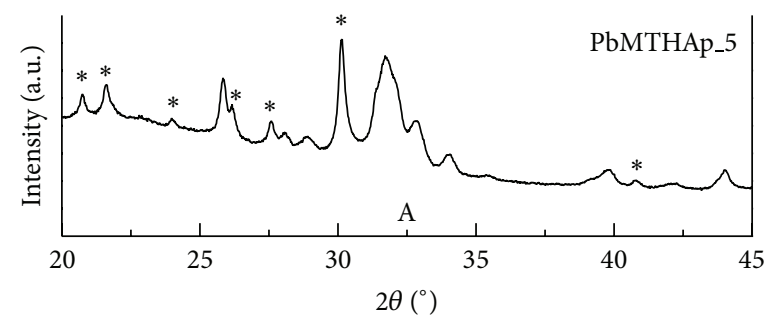

(b)

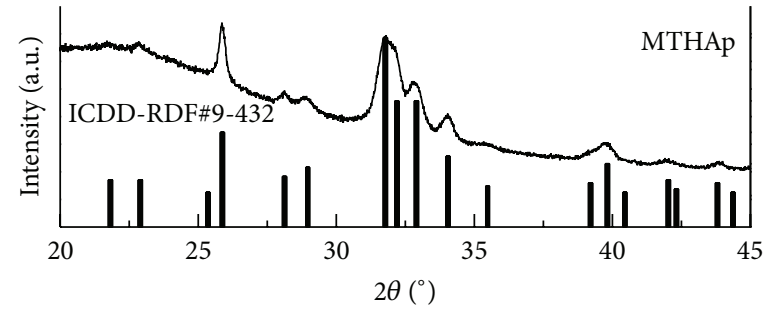

(c)

FIGURE 2: XRD patterns of hydroxyapatite coated with methyltrimethoxysilane before (MTHAp) and after the removal experiment of $\mathrm{Pb}^{2+}$ at pH 5 (PbMTHAp_5) and $\mathrm{pH} 3$ (PbMTHAp_3). ${ }^{*}$-represent the packs associated with overlapping of $\mathrm{Ca}_{2.5} \mathrm{~Pb}_{7.5}\left(\mathrm{PO}_{4}\right)_{6}\left(\mathrm{OH}_{2}\right.$ and $\mathrm{Pb}_{2} \mathrm{Ca}_{4}\left(\mathrm{PO}_{4}\right)_{2}\left(\mathrm{SiO}_{4}\right)$.

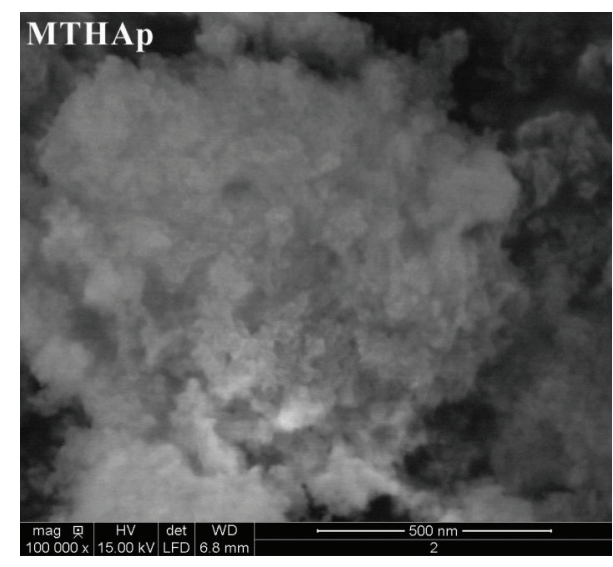

(a)

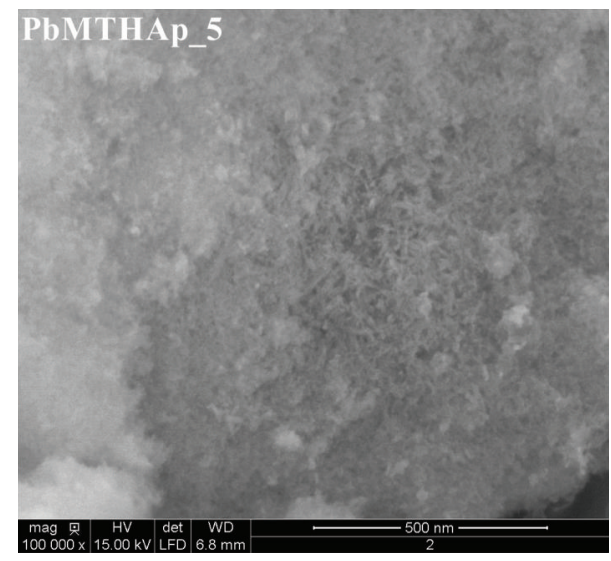

(b)

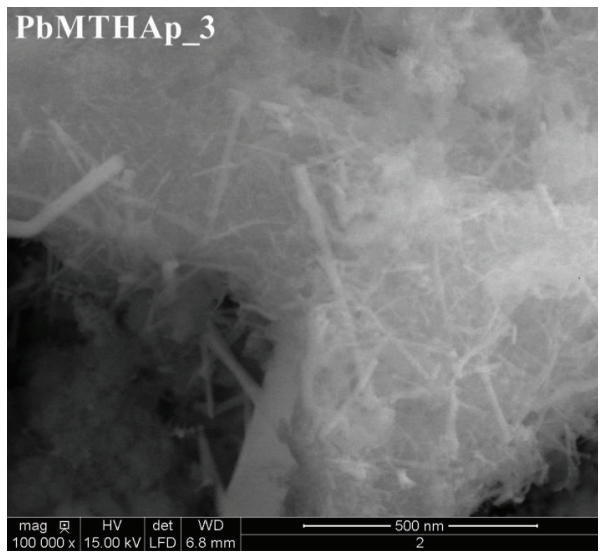

(c)

FIGURE 3: SEM micrographs of hydroxyapatite coated with methyltrimethoxysilane (MTHAp) before and after the reaction with a solution containing $950 \mathrm{mg}$ of $\mathrm{Pb} / \mathrm{L}$ at $\mathrm{pH} 5$ (PbMTHAp_5) and $\mathrm{pH} 3$ (PbMTHAp_3). 

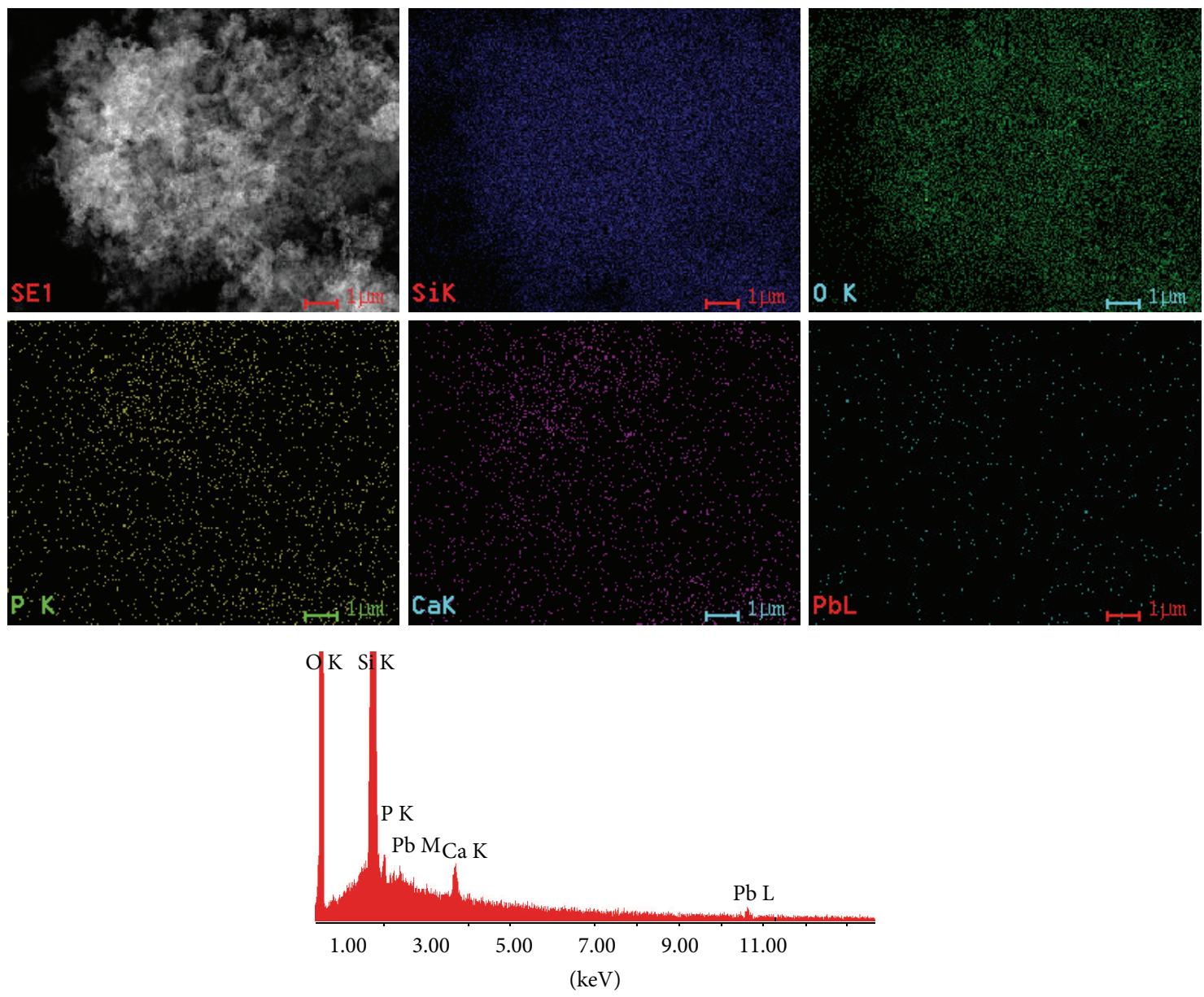

FIGURE 4: EDAX spectrum and element maps of silicium, oxygen, phosphorus, calcium, and lead after the reaction of hydroxyapatite coated with methyltrimethoxysilane with a solution containing $950 \mathrm{mg}$ of $\mathrm{Pb} / \mathrm{L}$ at $\mathrm{pH} 3$.

the MTHAp were dependent on the $\mathrm{pH}$ value. Distinct differences between the sample morphologies were observed in the SEM micrographs. The presence of $\mathrm{Ca}_{25} \mathrm{~Pb}_{75}\left(\mathrm{PO}_{4}\right)_{6}(\mathrm{OH})_{2}$ and $\mathrm{Pb}_{2} \mathrm{Ca}_{4}\left(\mathrm{PO}_{4}\right)_{2}\left(\mathrm{SiO}_{4}\right)$ crystals was identified by crystal clusters with needle or rod-like shapes. The quantity of $\mathrm{Ca}_{2.5} \mathrm{~Pb}_{7.5}\left(\mathrm{PO}_{4}\right)_{6}(\mathrm{OH})_{2}$ and $\mathrm{Pb}_{2} \mathrm{Ca}_{4}\left(\mathrm{PO}_{4}\right)_{2}\left(\mathrm{SiO}_{4}\right)$ crystals is more substantial for the solution with $\mathrm{pH} 3$ consistent with the XRD analysis. These results are in good agreement with preliminary studies [34].

In order to investigate the $\mathrm{Pb}$ absorption by the MTHAp samples, the EDAX mapping technique was used. In Figure 4 the EDAX spectrum and elemental mapping of hydroxyapatite coated with methyltrimethoxysilane after the reaction with a solution containing $950 \mathrm{mg}$ of $\mathrm{Pb} / \mathrm{L}$ at $\mathrm{pH} 3$ are presented.

The presence of $\mathrm{Si}, \mathrm{O}, \mathrm{P}, \mathrm{Ca}$, and $\mathrm{Pb}$ in the sample after the reaction with a solution containing $950 \mathrm{mg}$ of $\mathrm{Pb} / \mathrm{L}$ at $\mathrm{pH}$ 3 was revealed.

The impact of the lead concentration in the aqueous solution was studied by absorption experiments performed at $25^{\circ} \mathrm{C}$. For this purpose MTHAp concentration in the range of $0.1-0.9 \mathrm{~g} \cdot \mathrm{L}^{-1}$ at $\mathrm{pH} 5$ was used. The measurements were performed on $500 \mathrm{~mL}$ solution $(\mathrm{pH}$ ) with an initial

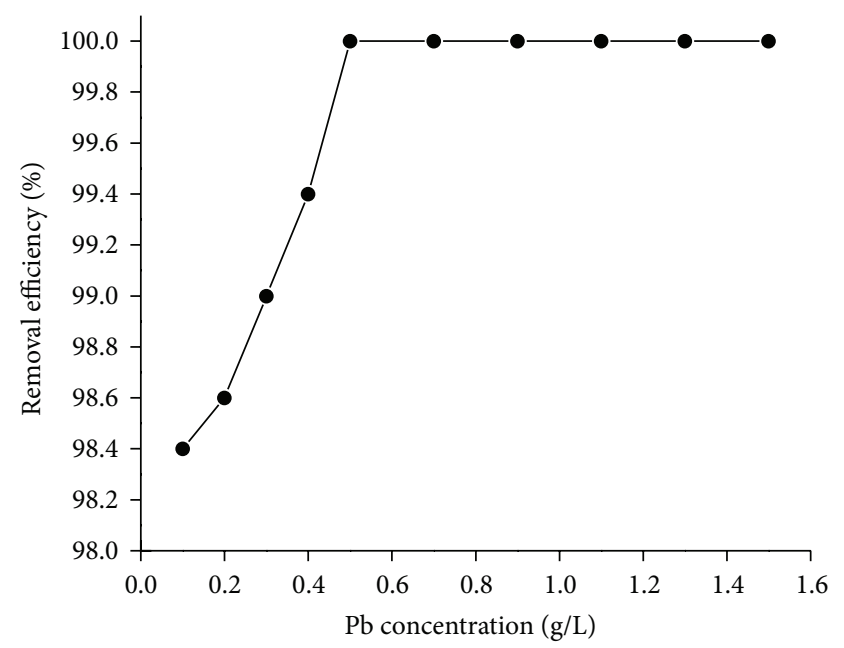

FIgURE 5: Effect of the $\mathrm{Pb}$ concentration on the removal of the $\mathrm{Pb}^{2+}$ ions by MTHAp.

$\mathrm{Pb}^{2+}$ ion concentration of $63 \mathrm{mg} \cdot \mathrm{L}^{-1}$. Figure 5 presents the adsorption efficiency of $\mathrm{Pb}^{2+}$ ions as a function of the $\mathrm{Pb}$ 


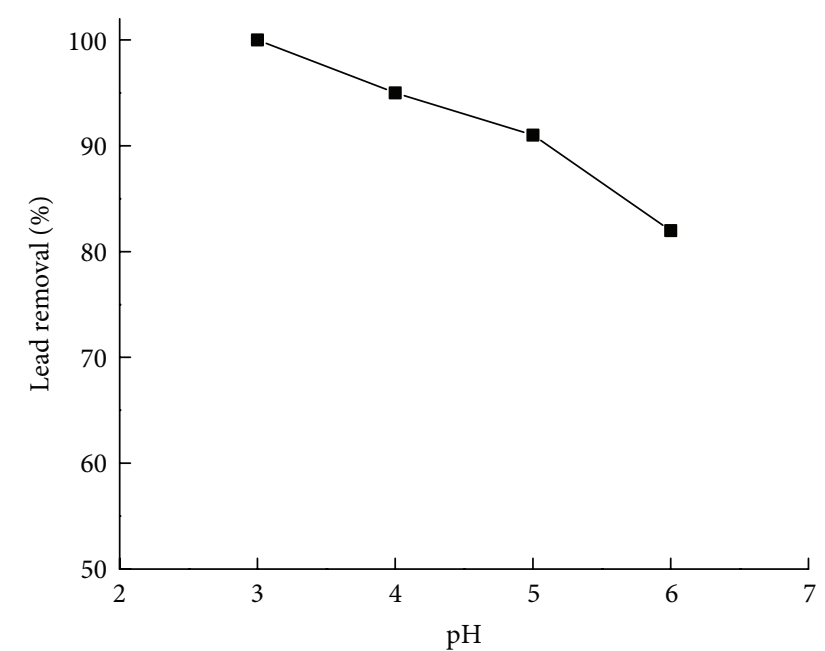

FIGURE 6: Effect of the solution $\mathrm{pH}$ on the removal of $\mathrm{Pb}^{2+}$ ions by MTHAp.

concentration in the solution. It was noticed that the removal efficiency increased proportionally with the $\mathrm{Pb}$ concentration. When a $\mathrm{Pb}$ concentration of $0.1 \mathrm{~g} \cdot \mathrm{L}^{-1}$ was used, the removal efficiency reached $98.4 \%$, showing that the adsorbent composite, MTHAp, had a strong affinity to $\mathrm{Pb}^{2+}$ ions. At $\mathrm{Pb}$ concentration from $0.5 \mathrm{~g} \cdot \mathrm{L}^{-1}$ to $1.5 \mathrm{~g} \cdot \mathrm{L}^{-1}$, the removal efficiency was nearly $100 \%$. In this case, the $\mathrm{Pb}^{2+}$ ions in the solution were completely removed. For the studies on the effect of the solution $\mathrm{pH}$, the lead concentration of $0.9 \mathrm{~g} \cdot \mathrm{L}^{-1}$ was chosen.

A solution containing $563 \mathrm{mg} \cdot \mathrm{L}^{-1}$ of $\mathrm{Pb}^{2+}$ ions was prepared from $0.9 \mathrm{~g}$ of $\mathrm{Pb}\left(\mathrm{NO}_{3}\right)_{2}$ in $1 \mathrm{~L}$ of distilled water. Figure 6 shows the measured $\mathrm{Pb}^{2+}$ ions concentration in the solution after the reaction with MTHAp has taken place.

At $\mathrm{pH} 3$, a removal efficiency of $100 \%$ was achieved. At $\mathrm{pH} 6$, the removal efficiency of $\mathrm{Pb}^{2+}$ ions was $82 \%$. For intermediate $\mathrm{pH}$ values, the removal efficiency of $\mathrm{Pb}^{2+}$ ions was $95 \%$ and $91 \%$ for $\mathrm{pH} 4$ and $\mathrm{pH} 5$, respectively.

As shown before, the influence of $\mathrm{pH}$ on the adsorption efficiency of lead is small. These results are in good agreement with the outcome of XRD and SEM analysis.

The theoretical Langmuir isotherm is often used to describe adsorption of a solute from a liquid solution as follows $[35,36]$ :

$$
q_{e}=\frac{q_{m} K_{L} C_{e}}{1+K_{L} C_{e}},
$$

where $q_{m}$ and $K_{L}$ are the Langmuir constants, which represent the maximum adsorption capacity for the solid phase loading and the energy constant related to the heat of adsorption, respectively. The two constants from the Langmuir isotherm can be determined by plotting $\left(1 / q_{e}\right)$ versus $\left(1 / C_{e}\right)$.

The experimental data and the Langmuir theoretical model are shown in Figure 7. The graph of $\mathrm{Pb}^{2+}$ adsorbed per unit mass of MTHAp, $q_{e}$, against the concentration of $\mathrm{Pb}^{2+}$ remaining in the solution, $C_{e}$, is shown. The coefficient of Langmuir isotherm at room temperature is $R^{2}=0.97305$.

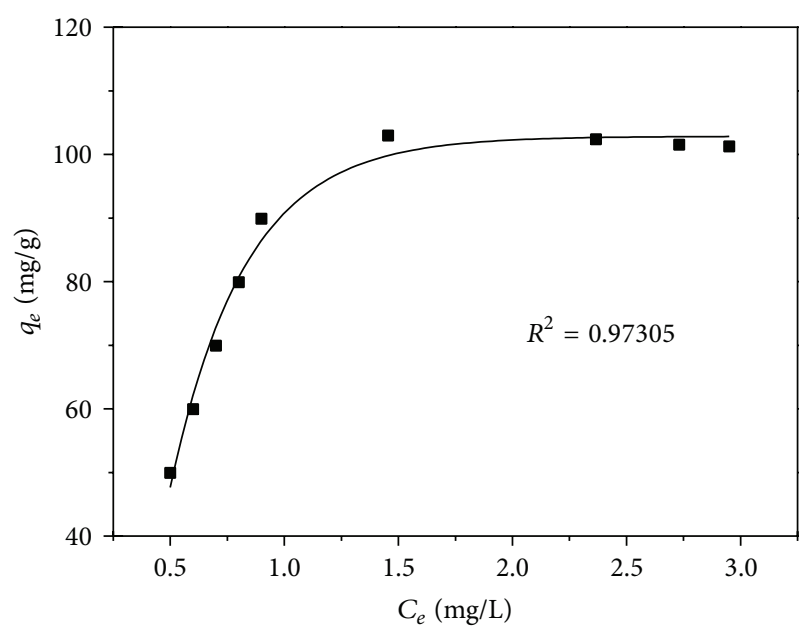

FIGURE 7: Langmuir isotherm obtained using the nonlinear method for the adsorption of $\mathrm{Pb}^{2+}$ onto hydroxyapatite coated with methyltrimethoxysilane.

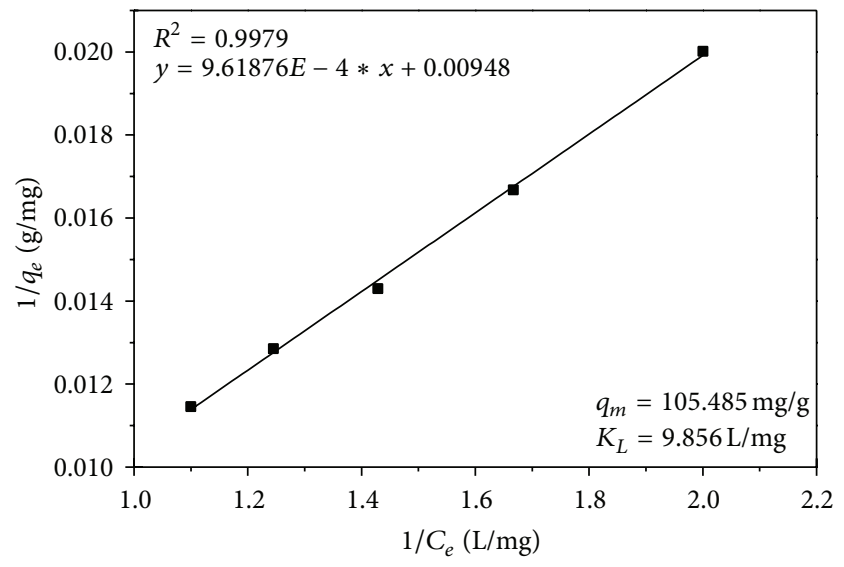

FIGURE 8: Langmuir adsorption isotherm for removal of $\mathrm{Pb}^{2+}$ by MTHAp.

In agreement with previous studies $[37,38]$ there was no problem with the transformation of nonlinear isotherm equation to linear form, by using nonlinear method.

Therefore, by plotting $\left(1 / q_{e}\right)$ versus $\left(1 / C_{e}\right)$, the two constants from the Langmuir isotherm were determined. Figure 8 shows the plots of the Langmuir isotherm model. It can be seen that the isotherm data fits the Langmuir equation with the highest value of the regression coefficients $R^{2}=$ 0.9979 . On the other hand, the maximum adsorption capacity for the solid phase $\left(q_{m}\right)$ is $105.485 \mathrm{mg}(\mathrm{Pb}) / \mathrm{g}(\mathrm{MTHAp})$. The Langmuir constant $K_{L}$ was found to be $9.856 \mathrm{~L} / \mathrm{mg}$.

Following these results, it can be emphasized that MTHAp can effectively remove $\mathrm{Pb}^{2+}$ ions from aqueous solutions. Because the $\mathrm{pH}$ of the groundwater and surface waters varies in the range of $5-7$, the $\mathrm{pH}$ value in the aqueous solution used for the removal of $\mathrm{Pb}^{2+}$ ions is an important parameter that must be considered [39]. Along with previous 
studies, such as [39], our study suggests that the solid reaction products of aqueous $\mathrm{Pb}$ with the apatite are $\mathrm{pH}$-dependent. In order to describe the uptake of different metals from aqueous solutions by synthetic hydroxyapatite [40-43] various processes have been proposed, such as cation exchange, metal complexation on the HAp surface, and apatite dissolution followed by a new metal phase precipitation. Suzuki et al., in their previous study [44], suggested the formation of a more stable lead apatite, such as $\mathrm{Ca}_{(10-x)} \mathrm{Pb}_{x}\left(\mathrm{PO}_{4}\right)_{6}(\mathrm{OH})_{2}$ via an ion exchange mechanism where $\mathrm{Pb}^{2+}$ present in the solution replaces $\mathrm{Ca}^{2+}$ ions from the hydroxyapatite lattice.

According to [45], $\mathrm{Pb}_{(10-x)} \mathrm{Ca}_{x}\left(\mathrm{PO}_{4}\right)_{6}(\mathrm{OH})_{2}$ crystals with higher content of calcium are unstable. As a consequence, the HAp would be subject to a continuous process of dissolution and precipitation leading to more stable structures with a higher lead content.

After the reaction of lead uptaken by MTHAp, dissolution of $\mathrm{Ca}_{10}\left(\mathrm{PO}_{4}\right)_{6}(\mathrm{OH})_{2}$ was involved, followed by the precipitation of solid solution of $\mathrm{Pb}$ and $\mathrm{Ca}$ as $\mathrm{Ca}_{2.5} \mathrm{~Pb}_{7.5}\left(\mathrm{PO}_{4}\right)_{6}(\mathrm{OH})_{2}$ and $\mathrm{Pb}_{2} \mathrm{Ca}_{4}\left(\mathrm{PO}_{4}\right)_{2}\left(\mathrm{SiO}_{4}\right)$. In agreement with previous studies [3], the formation of the new crystals was identified. Distinct morphologies were observed in the SEM micrographs. Scattered needle- or rod-shaped crystals were observed in the sample obtained from the reaction performed at low $\mathrm{pH}$. Ma et al. [46] reported similar crystals in previous studies. In agreement with former experiments [3, 18, 45, 46], the differences were detected under SEM between the unreacted apatite and those reacted under conditions of low $\mathrm{pH}$.

\section{Conclusions}

The objective of this study was to synthesize a new porous nanocomposite material based on methyltrimethoxysilane coated hydroxyapatite. Its ability to remove $\mathrm{Pb}^{2+}$ ions from aqueous solutions with a variety of initial $\mathrm{Pb}^{2+}$ ion concentrations and $\mathrm{pH}$ values from 3 to 5 was investigated. When MTHAp reacted with the solution containing $\mathrm{Pb}^{2+}$ ions, the lead ions were completely removed from the solution. The dissolution of $\mathrm{Ca}_{10}\left(\mathrm{PO}_{4}\right)_{6}(\mathrm{OH})_{2}$ occurred, forming $\mathrm{Ca}_{2.5} \mathrm{~Pb}_{7.5}\left(\mathrm{PO}_{4}\right)_{6}(\mathrm{OH})_{2}$ and $\mathrm{Pb}_{2} \mathrm{Ca}_{4}\left(\mathrm{PO}_{4}\right)_{2}\left(\mathrm{SiO}_{4}\right)$. The MTHAp composite material exhibited the higher removal efficiency of $\mathrm{Pb}^{2+}$ ions at low $\mathrm{pH}$. Its removal capacity was the highest at $\mathrm{pH} 3$ and the removal capacity of lead decreased slowly when the $\mathrm{pH}$ increased. After $24 \mathrm{~h}$, most of the $\mathrm{Pb}^{2+}$ ions were eliminated from the aqueous solution at various $\mathrm{pH}$ values and for an initial $\mathrm{Pb}$ concentration of $563 \mathrm{mg} \cdot \mathrm{L}^{-1}$. This research showed that the MTHAp nanocomposite material is a promising adsorbent for $\mathrm{Pb}^{2+}$ ions from aqueous solution at various $\mathrm{pH}$ values and could be used as a purifier for wastewaters.

\section{Conflict of Interests}

The authors declare that there is no conflict of interests regarding the publication of this paper.

\section{Acknowledgment}

The financial support and encouragement were provided by the Ministry of Educations of Romania under the Project IFACEA C2-06.

\section{References}

[1] W. Liang, L. Zhan, L. Piao, and C. Rüssel, "Lead and copper removal from aqueous solutions by porous glass derived calcium hydroxyapatite," Materials Science and Engineering B, vol. 176, no. 13, pp. 1010-1014, 2011.

[2] L. Dong, Z. Zhu, Y. Qiu, and J. Zhao, "Removal of lead from aqueous solution by hydroxyapatite/magnetite composite adsorbent," Chemical Engineering Journal, vol. 165, no. 3, pp. 827-834, 2010.

[3] A. Groza, "Review of the processes identified during the polymerization of organic and organosilicon liquid films in atmospheric pressure air corona discharges," Romanian Reports in Physics, vol. 64, supplement, pp. 1227-1242, 2012.

[4] M. Miyake, K. Ishigaki, and T. Suzuki, "Structure refinements of $\mathrm{Pb}^{2+}$ ion-exchanged apatites by $\mathrm{x}$-ray powder pattern-fitting," Journal of Solid State Chemistry, vol. 61, no. 2, pp. 230-235, 1986.

[5] J. Garcia-Leston, J. Mendez, E. Pasaro, and B. Laffon, "Genotoxic effects of lead: an updated review," Environment International, vol. 36, pp. 623-636, 2010.

[6] F. M. Johnson, "The genetic effects of environmental lead," Mutation Research-Reviews in Mutation Research, vol. 410, no. 2, pp. 123-140, 1998.

[7] F. Ge, M. Li, H. Ye, and B. Zhao, "Effective removal of heavy metal ions $\mathrm{Cd}^{2+}, \mathrm{Zn}^{2+}, \mathrm{Pb}^{2+}, \mathrm{Cu}^{2+}$ from aqueous solution by polymer-modified magnetic nanoparticles," Journal of Hazardous Materials, vol. 211-212, pp. 366-372, 2012.

[8] V. C. Taty-Costodes, H. Fauduet, C. Porte, and A. Delacroix, "Removal of $\mathrm{Cd}(\mathrm{II})$ and $\mathrm{Pb}$ (II) ions, from aqueous solutions, by adsorption onto sawdust of Pinus sylvestris," Journal of Hazardous Materials, vol. 105, no. 1-3, pp. 121-142, 2003.

[9] H. Ozaki, K. Sharma, and W. Saktaywin, "Performance of an ultra-low-pressure reverse osmosis membrane (ULPROM) for separating heavy metal: effects of interference parameters," Desalination, vol. 144, no. 1-3, pp. 287-294, 2002.

[10] K. Jainae, K. Sanuwong, J. Nuangjamnong, N. Sukpirom, and F. Unob, "Extraction and recovery of precious metal ions in wastewater by polystyrene-coated magnetic particles functionalized with 2-(3-(2aminoethylthio)propylthio)ethanamine," Chemical Engineering Journal, vol. 160, no. 2, pp. 586-593, 2010.

[11] Y. Feng, J. Gong, G. Zeng et al., "Adsorption of Cd (II) and $\mathrm{Zn}$ (II) from aqueous solutions using magnetic hydroxyapatite nanoparticles as adsorbents," Chemical Engineering Journal, vol. 162, no. 2, pp. 487-494, 2010.

[12] Q. Peng, Y. Liu, G. Zeng, W. Xu, C. Yang, and J.Zhang, "Biosorption of copper(II) by immobilizing Saccharomyces cerevisiae on the surface of chitosan-coated magnetic nanoparticles from aqueous solution," Journal of Hazardous Materials, vol. 177, no. 1-3, pp. 676-682, 2010.

[13] S. S. Banerjee and D. Chen, "Fast removal of copper ions by gum arabic modified magnetic nano-adsorbent," Journal of Hazardous Materials, vol. 147, no. 3, pp. 792-799, 2007.

[14] M. H. Mashhadizadeh and Z. Karami, "Solid phase extraction of trace amounts of $\mathrm{Ag}, \mathrm{Cd}, \mathrm{Cu}$, and $\mathrm{Zn}$ in environmental samples 
using magnetic nanoparticles coated by 3-(trimethoxysilyl)1-propantiol and modified with 2-amino-5-mercapto-1,3,4thiadiazole and their determination by ICP-OES," Journal of Hazardous Materials, vol. 190, no. 1-3, pp. 1023-1029, 2011.

[15] R. R. Sheba, "Sorption behaviour of Zn(II) ions on synthesized hydroxyapatites," Journal of Colloid and Interface Science, vol. 310, pp. 18-26, 2007.

[16] A. Krestou, A. Xenidis, and D. Panias, "Mechanism of aqueous uranium(VI) uptake by hydroxyapatite," Minerals Engineering, vol. 17, no. 3, pp. 373-381, 2004.

[17] S. H. Jang, Y. G. Jeong, B. G. Min, W. S. Lyoo, and S. C. Lee, "Preparation and lead ion removal property of hydroxyapatite/polyacrylamide composite hydrogels," Journal of Hazardous Materials, vol. 159, no. 2-3, pp. 294-299, 2008.

[18] A. Yasukawa, T. Yokoyama, K. Kandori, and T. Ishikawa, "Reaction of calcium hydroxyapatite with $\mathrm{Cd}^{2+}$ and $\mathrm{Pb}^{2+}$ ions," Colloids and Surfaces A: Physicochemical and Engineering Aspects, vol. 299, no. 1-3, pp. 203-208, 2007.

[19] I. Smiciklas, A. Onjia, S. Raicević, D. Janaćković, and M. Mitrić, "Factors influencing the removal of divalent cations by hydroxyapatite," Journal of Hazardous Materials, vol. 152, pp. 876-884, 2008.

[20] A. Costescu, I. Pasuk, F. Ungureanu et al., "Physico-chemical properties of nano-sized hexagonal hydroxyapatite powder synthesized by sol-gel," Digest Journal of Nanomaterials and Biostructures, vol. 5, no. 4, pp. 989-1000, 2010.

[21] D. Dieterich, E. Grigat, W. Hahn, H. Hespe, and H. G. Schmelzer, "Principles of polyurethane chemistry and special applications," in Polyurethane Handbook: Chemistry, Raw Materials, Processing, Application, Properties, G. Oertel, Ed., pp. 11-31, Hanser, Munich, Germany, 2nd edition, 1994.

[22] C. S. Ciobanu, S. L. Iconaru, F. Massuyeau, L. V. Constantin, A. Costescu, and D. Predoi, "Synthesis, structure, and luminescent properties of europium-doped hydroxyapatite nanocrystalline powders," Journal of Nanomaterials, vol. 2012, Article ID 942801, 9 pages, 2012.

[23] C. S. Ciobanu, E. Andronescu, A. Stoicu et al., "Influence of annealing treatment of nano-hydroxyapatite bioceramics on the vibrational properties," Digest Journal of Nanomaterials and Biostructures, vol. 6, no. 2, pp. 609-624, 2011.

[24] A. Ślósarczyk, Z. Paszkiewicz, and C. Paluszkiewicz, "FTIR and XRD evaluation of carbonated hydroxyapatite powders synthesized by wet methods," Journal of Molecular Structure, vol. 744-747, pp. 657-661, 2005.

[25] M. Lebon, I. Reiche, F. Fröhlich, J.-. Bahain, and C. Falguères, "Characterization of archaeological burnt bones: Contribution of a new analytical protocol based on derivative FTIR spectroscopy and curve fitting of the $v_{1} v_{3} \mathrm{PO}_{4}$ domain," Analytical and Bioanalytical Chemistry, vol. 392, no. 7-8, pp. 1479-1488, 2008.

[26] I. R. Gibson, S. M. Best, and W. Bonfield, "Chemical characterization of silicon-substituted hydroxyapatite," Journal of Biomedical Materials Research, vol. 44, pp. 422-428, 1999.

[27] M. A. Karakassides, D. Gournis, and D. Petridis, "An infrared reflectance study of Si-O vibrations in thermally treated alkalisaturated montmorillonites," Clay Minerals, vol. 34, no. 3, pp. 429-438, 1999.

[28] E. Bogya, R. Barabás, A. Csavdári, V. Dejeu, and I. Bâldea, "Hydroxyapatite modified with silica used for sorption of copper(II)," Chemical Papers, vol. 63, no. 5, pp. 568-573, 2009.
[29] A. Groza, A. Surmeian, M. Ganciu, R. Medianu, and I. I. Popescu, " $\mathrm{SIO}_{2}$ - Like thin films generation in corona discharges in air at atmospheric pressure: an IR spectroscopy and atomic force microscopy investigations," Journal of Optoelectronics and Advanced Materials, vol. 7, no. 4, pp. 2159-2164, 2005.

[30] A. Groza, A. Surmeian, M. Ganciu, and I. I. Popescu, "Infrared spectral investigation of organosilicon compounds under corona charge injection in air at atmospheric pressure," Journal of Optoelectronics and Advanced Materials, vol. 7, no. 5, pp. 2545-2548, 2005.

[31] R. S. Zhai, A. Das, C. K. Hsu et al., "Polymeric fullerene oxide films produced by decomposition of hexanitro[60]fullerene," Carbon, vol. 42, no. 2, pp. 395-403, 2004.

[32] S. K. Lower, P. A. Maurice, and S. J. Traina, "Simultaneous dissolution of hydroxylapatite and precipitation of hydroxypyromorphite: Direct evidence of homogeneous nucleation," Geochimica et Cosmochimica Acta, vol. 62, no. 10, pp. 1773-1780, 1998.

[33] C. Y. Kim, H. J. Kim, and J. S. Nam, "Removal of lead ions from solution by phosphosilicate glass," Journal of Hazardous Materials, vol. 153, no. 1-2, pp. 173-178, 2008.

[34] F. Zhang, Z. Zhao, R. Tan, W. Xu, G. Jiang, and W. Song, "Efficient and selective immobilization of $\mathrm{Pb}^{2+}$ in highly acidic wastewater using strontium hydroxyapatite nanorods," Chemical Engineering Journal, vol. 203, pp. 110-114, 2012.

[35] I. Langmuir, "The adsorption of gases on plane surfaces of glass, mica and platinum," The Journal of the American Chemical Society, vol. 40, no. 9, pp. 1361-1403, 1918.

[36] Y. S. Ho, C. T. Huang, and H. W. Huang, "Equilibrium sorption isotherm for metal ions on tree fern," Process Biochemistry, vol. 37, no. 12, pp. 1421-1430, 2002.

[37] Y. S. Ho, "Selection of optimum sorption isotherm," Carbon, vol. 42, no. 10, pp. 2115-2116, 2004.

[38] J. He, S. Hong, L. Zhang, F. Gan, and Y. Ho, "Equilibrium and thermodynamic parameters of adsorption of methylene blue onto rectorite," Fresenius Environmental Bulletin, vol. 19, no. 11A, pp. 2651-2656, 2010.

[39] S. H. Jang, B. G. Min, Y. G. Jeong, W. S. Lyoo, and S. C. Lee, "Removal of lead ions in aqueous solution by hydroxyapatite/polyurethane composite foams," Journal of Hazardous Materials, vol. 152, no. 3, pp. 1285-1292, 2008.

[40] Q. Y. Ma, S. J. Traina, T. J. Logan, and J. A. Ryan, "In situ lead immobilization by apatite," Environmental Science and Technology, vol. 27, no. 9, pp. 1803-1810, 1993.

[41] A. G. Leyva, J. Marrero, P. Smichowski, and D. Cicerone, "Sorption of antimony onto hydroxyapatite," Environmental Science and Technology, vol. 35, no. 18, pp. 3669-3675, 2001.

[42] T. Suzuki, T. Hatsushika, and Y. Hayakawa, "Synthetic hydroxyapatites employed as inorganic cation-exchangers," Journal of the Chemical Society, Faraday Transactions, vol. 77, no. 5, pp. 1059-1062, 1981.

[43] Y. Suzuki and Y. Takeuchi, "Uptake of a few divalent heavy metal ionic species by a fixed bed of hydroxyapatite particles," Journal of Chemical Engineering of Japan, vol. 27, no. 5, pp. 571-576, 1994.

[44] T. Suzuki, K. Ishigaki, and M. Miyake, "Synthetic hydroxyapatites as inorganic cation exchangers-part 3-Exchange characteristics of lead ions $\left(\mathrm{Pb}^{2+}\right)$," Journal of the Chemical Society, Faraday Transactions 1: Physical Chemistry in Condensed Phases, vol. 80, no. 11, pp. 3157-3165, 1984. 
[45] G. Lusvardi, G. Malavasi, L. Menabue, and M. Saladini, "Removal of cadmium ion by means of synthetic hydroxyapatite," Waste Management, vol. 22, pp. 853-857, 2002.

[46] Q. Y. Ma, T. J. Logan, and S. J. Traina, "Lead immobilization from aqueous solutions and contaminated soils using phosphate rocks," Environmental Science and Technology, vol. 29, no. 4, pp. 1118-1126, 1995. 

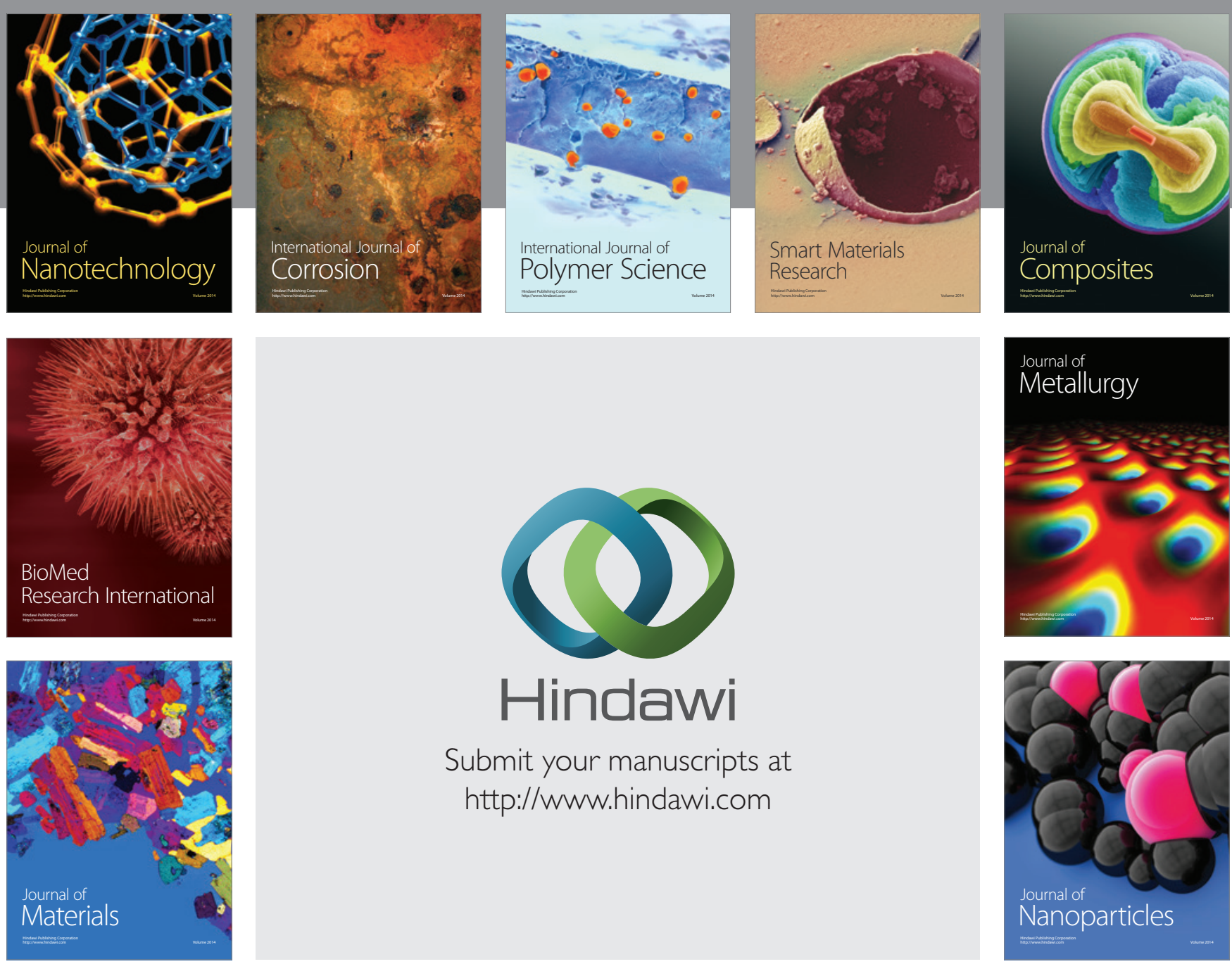

Submit your manuscripts at http://www.hindawi.com
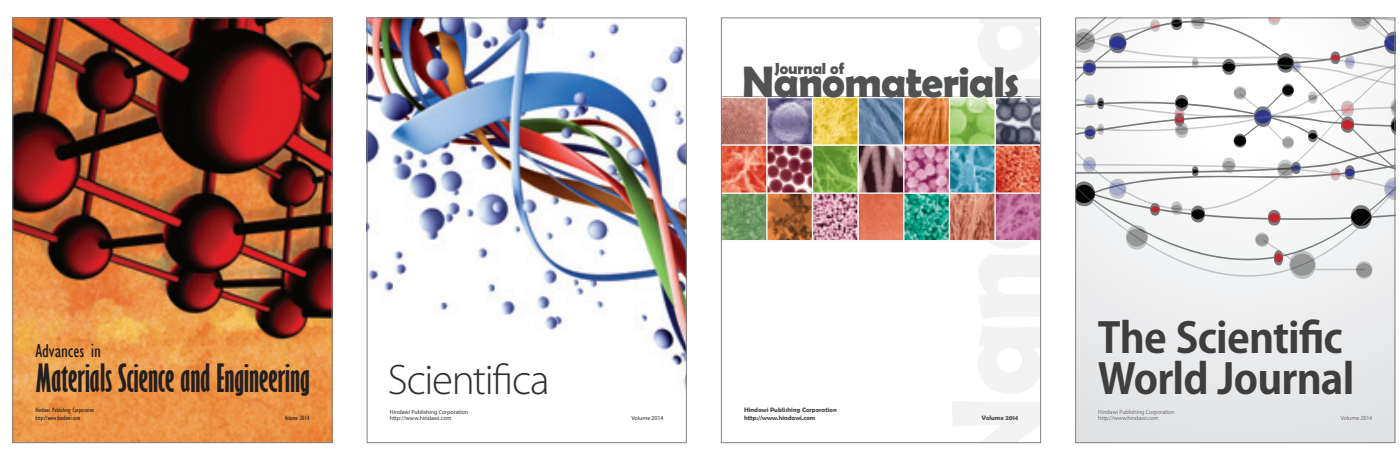

\section{The Scientific World Journal}
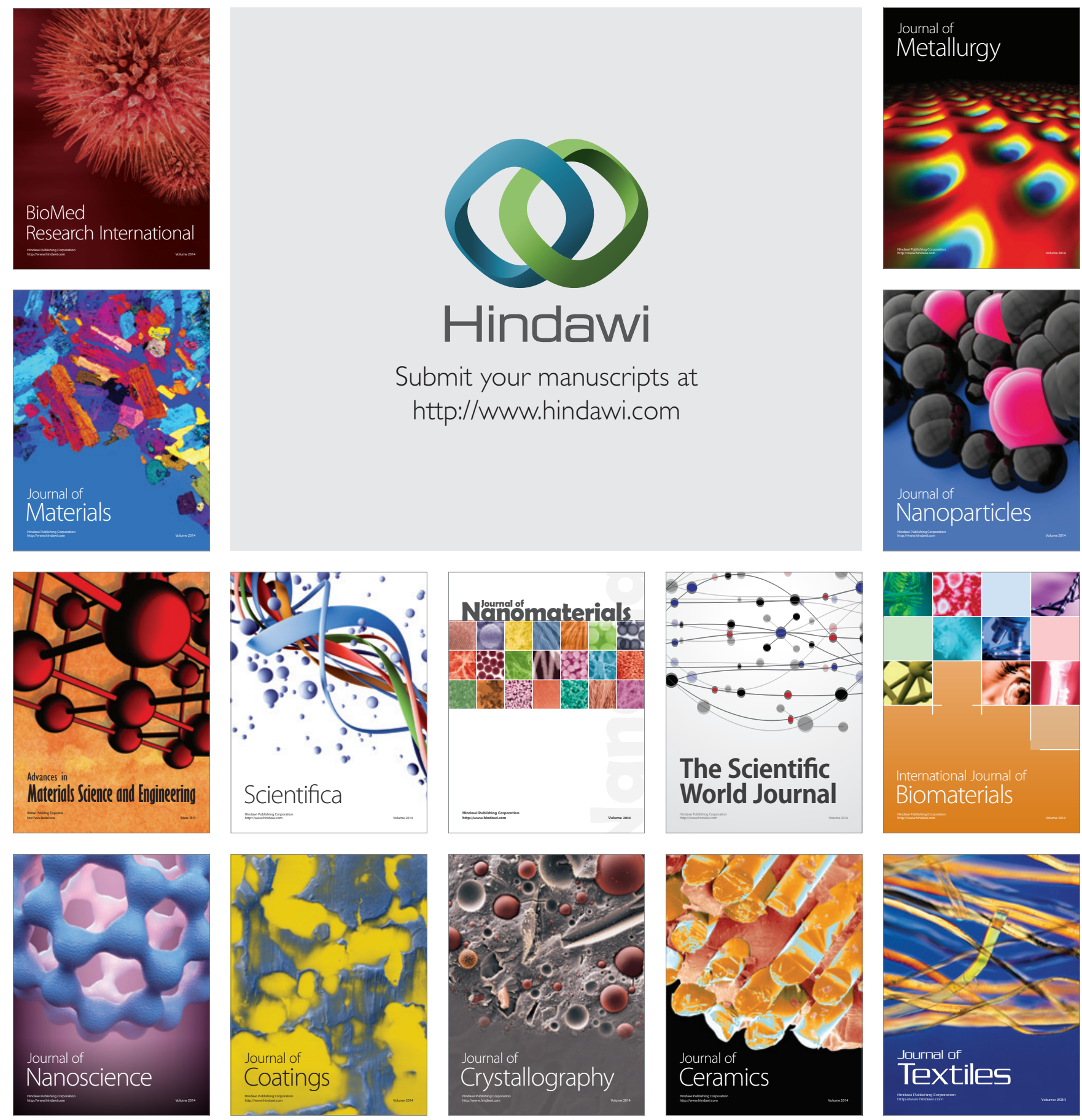